\title{
Prominence of Medullary Veins on Susceptibility-Weighted Images Provides Prognostic Information in Patients with Subacute Stroke
}

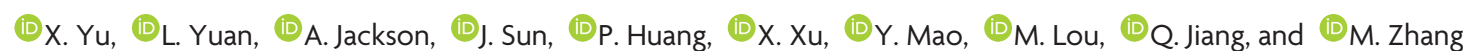

\begin{abstract}
BACKGROUND AND PURPOSE: The demonstration of prominent medullary veins in the deep white matter ipsilateral to acute ischemic stroke has been shown to predict poor clinical outcome. We have investigated the prognostic implications of prominent medullary veins in patients with subacute stroke who present outside the therapeutic window for revascularization therapy.
\end{abstract}

MATERIALS AND METHODS: Forty-three consecutive patients with ischemic stroke in the middle cerebral artery territory presenting within 3-7 days of ictus were enrolled. The presence of prominent medullary veins in the periventricular white matter of the ipsilateral and contralateral medullary vein hemispheres was recorded. Perfusion-weighted imaging was used to calculate differences in hemispheric CBF from corresponding areas. Clinical outcome was classified as good if the modified Rankin Scale score was $<3$.

RESULTS: Prominent medullary veins were observed in 24/43 patients with 14 ipsilateral medullary veins and 10 contralateral medullary veins. The ipsilateral medullary vein was independently associated with poor outcome (odds ratio, 11.19; $P=.046$ ). The contralateral medullary vein was not independently predictive of outcome but was significantly more common in patients with good outcome ( $90.0 \%$ contralateral medullary veins). A mean $64.5 \%$ decrease and a $52.4 \%$ increase of differences in hemispheric CBF were found in ipsilateral medullary veins and contralateral medullary veins, respectively.

CONCLUSIONS: The ipsilateral medullary vein was a significant predictive biomarker of poor clinical outcome after stroke and was associated with hypoperfusion. The contralateral medullary vein was associated with good clinical outcome, and we hypothesize that prominent contralateral medullary veins indirectly reflect increased CBF in the ipsilateral hemisphere due to spontaneous recanalization or collateral flow.

ABBREVIATIONS: $\triangle \mathrm{CBF}=$ differences in hemispheric $\mathrm{CBF} ; \mathrm{MV}=$ medullary veins; $\mathrm{MV} \mathrm{c}=$ contralateral medullary veins; $\mathrm{MVi}=$ ipsilateral medullary veins; Norm $=$ normal appearances; $\mathrm{TIMI}=$ Thrombolysis in Myocardial Infarction

n recent years, several groups, by using SWI in patients with acute ischemic stroke, have observed prominent cerebral medullary veins (MV) in the centrum semiovale and corona

Received May 18, 2015; accepted after revision July 29.

From the Departments of Radiology (X.Y., J.S., P.H., X.X., M.Z.) and Neurology (Y.M., M.L.), Second Affiliated Hospital of Zhejiang University School of Medicine, Hangzhou, China; Department of Biomedical Engineering and Instrument Science (L.Y.), Key Laboratory for Biomedical Engineering of Education Ministry of China, Zhejiang University, Hangzhou, China; Wolfson Molecular Imaging Centre (A.J.), University of Manchester, Manchester, United Kingdom; and Department of Neurology (Q.J), Henry Ford Health System, Detroit, Michigan.

This work was supported by the National Natural Science Foundation of China (No. 81271530) and the Zhejiang Provincial Natural Science Foundation of China (No. LZ14H180001).

Please address correspondence to Minming Zhang, MD, PhD, Department of Radiology, Second Affiliated Hospital of Zhejiang University School of Medicine, No. 88 Jiefang Rd, Shangcheng District, Hangzhou, China, 310009; e-mail: zhangminming@zju.edu.cn

- Indicates open access to non-subscribers at www.ajnr.org

http://dx.doi.org/10.3174/ajnr.A4541 radiata. ${ }^{1-3}$ It has been hypothesized that the prominence of MV may be due to increased deoxyhemoglobin content due to an increase in regional oxygen extraction in the drainage territory ${ }^{1,4-6}$ and/or dilation of cerebral veins in response to ischemia. ${ }^{3,7}$ Subsequent studies have shown that abnormal hypointensity of the MV is correlated with a prolonged mean transit time, a large perfusion defect, ${ }^{7}$ and increased cerebral blood volume. ${ }^{8}$ The presence of prominent dilated MV in the periventricular white matter on SWI has been called the "brush sign."

Identification of patients with acute stroke in whom misery perfusion results in increases in oxygen extraction is potentially important as a stratification and predictive biomarker. One recent study of 36 patients with acute stroke reported a significantly higher incidence of hemorrhagic transformation in patients with prominent $\mathrm{MV}$ ( $64 \%$ versus $18 \%, P=.028){ }^{2}$ Our recent study of 54 patients undergoing thrombolytic therapy found that asymmetry of the MV, combined with the size of the diffusion defect, was highly predictive of favorable out- 
come for reperfusion and recanalization with an accuracy greater than that of perfusion-diffusion mismatch. ${ }^{9}$

Prominence of the MV is also seen in the subacute stage of ischemic stroke. ${ }^{10}$ In clinical practice, we have noted that prominent MV may be seen ipsilateral or contralateral to infarction. Such imaging signs may provide important prognostic information to guide clinicians toward the application of tissue-rescue therapies (such as recanalization or vasodilation) to prevent stroke progression during the subacute phase. We have therefore used SWI combined with dynamic contrast-enhanced MR imaging to test the following hypotheses: 1) Prominent ipsilateral MV are prognostic biomarkers of poor outcome in patients with subacute ischemic stroke; 2) prominent ipsilateral MV are associated with hypoperfusion; and 3) prominent contralateral MV provide additional prognostic information.

\section{MATERIALS AND METHODS}

\section{Patients}

The study was approved by the Medical Ethics Committee of the Second Affiliated Hospital of Zhejiang University School of Medicine, and written informed consent was obtained from all subjects.

Recruitment took place between March 2012 and January 2014. Inclusion criteria were the following: first-ever ischemic stroke, involving the vascular territory of the unilateral middle cerebral artery, without hemorrhagic infarction; age older than 18 years; admission between 3 and 7 days after stroke onset; and National Institutes of Health Stroke Scale score of 5-21 on admission. Exclusion criteria were any evidence of previous stroke on initial brain MRI. No patients were treated with thrombolytic or recanalization therapies. Demographic information and vascular risk factors, including age, sex, diabetes mellitus, hypertension, hyperlipidemia, and smoking and drinking histories, were recorded. Neurologic impairment on admission was assessed by using the NIHSS score. Clinical outcome at 3 months was evaluated by using the modified Rankin Scale ${ }^{11}$ : $(\operatorname{good}$ outcome $=$ $m R S<3$ ). The NIHSS and $m R S$ were assessed by an experienced stroke neurologist who was blinded to the imaging findings.

\section{MR Imaging Protocol}

Brain MR images were obtained on a 3T scanner (Signa Excite; GE Healthcare, Milwaukee, Wisconsin) by using an 8-channel brain phased array coil. Susceptibility-weighted images were acquired by using a $3 \mathrm{D}$ high-resolution flow-compensated multiecho gradient-echo sequence $(\mathrm{TR} / \mathrm{TE}=45 / 5-35 \mathrm{~ms}, 6$ echoes with an echo spacing of $6.048 \mathrm{~ms}$, flip angle $=25^{\circ}$, section thickness $=2$ $\mathrm{mm}$, matrix $=384 \times 320$ interpolated into $512 \times 512, \mathrm{FOV}=24$ $\mathrm{cm})$. MRA was acquired by using a $3 \mathrm{D}$ time-of-flight sequence $\left(\mathrm{TR} / \mathrm{TE}=20 / 3.2 \mathrm{~ms}\right.$, flip angle $=15^{\circ}$, section thickness $=1.4$ $\mathrm{mm}$, matrix $=320 \times 224, \mathrm{FOV}=24 \mathrm{~cm})$. DWI was acquired by using an echo-planar imaging sequence $(\mathrm{TR} / \mathrm{TE}=4000 / 78.5 \mathrm{~ms}$, flip angle $=90^{\circ}$, section thickness $=4 \mathrm{~mm}$, section gap $=1 \mathrm{~mm}$, matrix $=256 \times 256$, FOV $=24 \mathrm{~cm}$ ) by using a single b-value of $1000 \mathrm{~s} / \mathrm{mm}^{2}$ applied in 3 orthogonal directions. PWI was performed by using a $\mathrm{T} 2{ }^{\star}$ sensitive gradient-echo EPI sequence (TR/ $\mathrm{TE}=1700 / 30 \mathrm{~ms}$, flip angle $=60^{\circ}$, section thickness $=4 \mathrm{~mm}$, section gap $=1 \mathrm{~mm}$, matrix $=128 \times 128$, FOV $=24 \mathrm{~cm})$. Sixty time points were acquired with a temporal resolution of $1.7 \mathrm{sec}-$ onds. Contrast agent (Gd-DTPA, Ominscan; GE Healthcare, Piscataway, New Jersey), 0.1-mmol/kg body weight, was administered via an antecubital vein at a rate of $4 \mathrm{~mL} / \mathrm{s}$ followed by a 20 - $\mathrm{mL}$ saline flush injected at the same rate following the T1weighted scan acquisition.

\section{Image Processing and Analysis}

The latter 3 echoes ( $\mathrm{TE}=23.144,29.192$, and $35.240 \mathrm{~ms}$ ) of multiecho susceptibility-weighted images were averaged to improve the conspicuity of the MV. ${ }^{12}$ Each echo of the SWI was processed by using a high-pass filter $(64 \times 64)$ followed by phase multiplication by using a factor of 4 and production of a minimum intensity projection over 3 sections based on the magnitude and phase images by using the signal processing in NMR software (Wayne State University, Detroit, Michigan). The presence of prominent MV was assessed at the level of periventricular white matter (from immediately above the basal ganglia to the highest section including ventricle) on the axial plane of the synthesized MIP susceptibility-weighted images. ${ }^{9}$ Prominence of the MV was defined as an increased number of MV in 1 hemisphere with at least 5 more seen in comparison with the contralateral hemisphere. This criterion was adapted from the scoring schema described by Horie et al. ${ }^{13}$ We did not use the entire grading scale described by Horie et al because we were interested only in the significance of increased $\mathrm{MV}$, so we adopted their cutoff value of a hemispheric asymmetry of $>5$. A neurologist and a radiologist, each blinded to the results of the other and to the clinical data and other MR images, performed the assessment. In the case of discrepancies, consensus was reached through discussion. Figure 1 shows the examples of ipsilateral MV (MVi), contralateral MV (MVc), and normal appearances (Norm).

Parametric maps of CBF were derived from PWI by using Perfusion Mismatch Analyzer software (http://asist.umin.jp/ index-e.htm). CBF was measured in the territory of the medullary veins corresponding to their location on susceptibilityweighted images by using symmetric ROIs between 2.4 and 3.0 $\mathrm{cm}^{3}$ (red rectangular ROIs shown on the CBF images in Fig 1). The hemispheric perfusion ratio (differences in hemispheric $\mathrm{CBF}[\Delta \mathrm{CBF}])$ was calculated as:

$$
\Delta \mathrm{CBF}=\left(\mathrm{CBF}_{\text {affected side }}-\mathrm{CBF}_{\text {normal side }}\right) / \mathrm{CBF}_{\text {normal side }} \times 100 \% .
$$

Hypoperfusion and hyperperfusion were respectively defined as a decrease or increase of $\Delta \mathrm{CBF}$ of $>20 \%$ compared with the contralateral hemisphere. ${ }^{14}$

The size of the ischemic lesion on DWI was determined by using a semiautomated threshold algorithm to identify the area with an intensity greater than the mean plus 2 SDs of the value in the homologous contralateral region. ${ }^{15}$

The vascular status was identified on MRA by 2 radiologists who gave a consensus rating by using the Thrombolysis in Myocardial Infarction (TIMI) grading scale ${ }^{16}: 0=$ complete occlusion, $1=$ severe stenosis, $2=$ mild or moderate stenosis, and $3=$ normal. We categorized vascular status into 3 subgroups: occlusion (TIMI 0), stenosis (TIMI 1-2), and normal (TIMI 3). At the same time, the site of arterial stenosis-occlusion was also evaluated. 


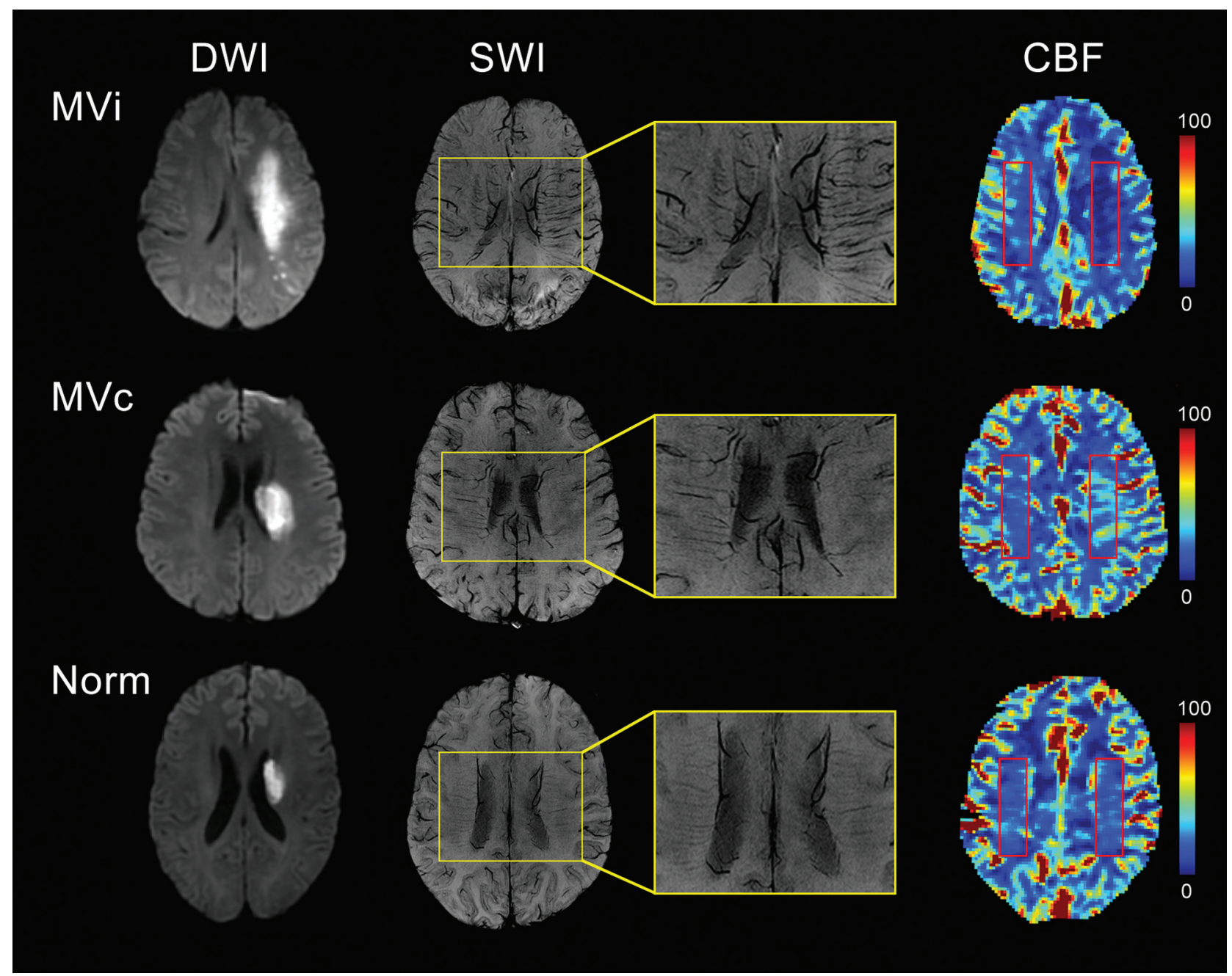

FIG 1. Examples of prominent medullary veins on susceptibility-weighted imaging with corresponding diffusion-weighted images and cerebral blood flow maps. Top row: Ipsilateral MV are seen in the deep white matter ipsilateral to the diffusion abnormality. CBF maps show decreased white matter perfusion in the corresponding area. Red rectangles illustrate the position of the ROls used for calculation of $\triangle C B F$. Middle row: Contralateral MV are illustrated in the deep white matter contralateral to the diffusion abnormality. CBF maps show increased white matter perfusion in the corresponding area. Bottom row: Normal appearances. Susceptibility-weighted images show no evidence of prominent MV.

\section{Statistical Analysis}

Continuous variables are shown as mean $\pm \mathrm{SD}$ or median (interquartile range), whereas categoric variables are presented as absolute and relative frequencies. Interrater reliability of prominent MV was assessed by using $\kappa$ statistics. The clinical and imaging variables between good and poor outcome groups were analyzed by using a 2 -sample independent $t$ test or a Mann-Whitney $U$ test for continuous variables and a Pearson $\chi^{2}$ test or Fisher exact test for categoric variables. Univariate and multivariate logistic regression (forward method) models were used to determine the independent contribution of factors to clinical outcome. Specific variables (age, sex, NIHSS, and DWI lesion size) were preselected for entry into the model. Other variables were selected for entry into the model if the differences between good and poor outcome groups were significant at the $P<.1$ level. The clinical and imaging variables among the 3 groups $(\mathrm{MVi}, \mathrm{MVc}$, and Norm) were compared by using 1-way ANOVA or the Kruskal-Wallis test for continuous variables and the Pearson $\chi^{2}$ test or Fisher exact test for categoric variables. The independent factors associated with $\mathrm{MVi}$ and $\mathrm{MVc}$ were analyzed by using multivariate logistic regres- sion analysis. Variables were selected for entry into the model only if the Spearman correlation coefficient was less than a 0.5 level. Odds ratios with their $95 \%$ confidence intervals of factors in logistic regression analysis were estimated. A 2-tailed value of $P<.05$ was considered significant. Statistical analysis was performed by using SPSS 20.0 for Windows software (IBM, Armonk, New York).

\section{RESULTS}

\section{Patient Characteristics}

Forty-three patients were recruited (mean age, $59.1 \pm 12.4$ years; range, 36 to 80 years); $25 / 43$ (58.1\%) were men. The time between MR imaging and symptom onset was $4.9 \pm 1.4$ days (range, $3-7$ days). The NIHSS score on admission was $9.8 \pm 3.5$ (range, $5-17$ ).

\section{Interrater Agreement for Evaluation of Prominent MV}

Interrater agreement for the evaluation of prominent MV was excellent $(\kappa=0.927)$, as it was for MVi $(\kappa=0.937)$ and MVc $(\kappa=$ 0.922). Prominent MV were seen in $24 / 43$ (55.8\%) patients, with 14 (32.6\%) MVi and 10 (23.2\%) MVc.

AJNR Am J Neuroradiol 37:423-29 Mar 2016 www.ajnr.org 


\section{Factors Associated with Clinical Outcome}

Twenty-four of 43 (55.8\%) patients were classified as having good outcome, and 19/43 (44.2\%), as having poor outcome. There were significant differences between the 2 groups in age $(P=.008)$, admission NIHSS score $(P=.002)$, site of arterial steno-occlusion $(P=.085)$, and prominent $\mathrm{MV}(P=.003)$ (Table $1)$. Both MVi $(P<.01)$ and MVc $(P<.05)$ were significantly different between groups. MVi were significantly more common in the poor outcome group (57.9\% versus $12.5 \%$, $P=.002)$, and MVc were significantly more common in the good outcome group (37.5\% versus 5.3\%, $P=.026)$. Multivariate regression analysis demonstrated that MVi (OR, 11.19;

Table 1: Clinical and imaging characteristics between patients with good/poor outcome

\begin{tabular}{|c|c|c|c|}
\hline Variable & $\begin{array}{l}\text { Good Outcome } \\
\qquad(n=24)\end{array}$ & $\begin{array}{l}\text { Poor Outcome } \\
\qquad(n=19)\end{array}$ & $P$ Value \\
\hline Age (mean) (yr) & $54.7 \pm 11.0$ & $64.6 \pm 12.1$ & $.008^{\mathrm{a}}$ \\
\hline Men (No.) (\%) & $12(50.0)$ & $13(68.4)$ & .224 \\
\hline Time to MRI examination (mean) (day) & $5.1 \pm 1.4$ & $4.8 \pm 1.4$ & .489 \\
\hline Admission NIHSS score (mean) & $8.4 \pm 3.3$ & $11.5 \pm 2.9$ & $.002^{\mathrm{a}}$ \\
\hline \multicolumn{4}{|l|}{ Vascular risk factors } \\
\hline Diabetes mellitus (No.) (\%) & $11(45.8)$ & $9(47.4)$ & .920 \\
\hline Hypertension (No.) (\%) & $11(45.8)$ & $7(36.8)$ & .553 \\
\hline Hyperlipidemia (No.) (\%) & $10(41.7)$ & $12(63.2)$ & .161 \\
\hline Smoking (No.) (\%) & $8(33.3)$ & $7(36.8)$ & .811 \\
\hline Drinking (No.) (\%) & $6(25.0)$ & $5(26.3)$ & 1.000 \\
\hline Lesion left location (No.) (\%) & $15(62.5)$ & $8(42.1)$ & .183 \\
\hline Vascular status (TIMI) & & & .285 \\
\hline Occlusion (TIMI 0) & $9(37.5)$ & $11(57.9)$ & \\
\hline Stenosis (TIMI 1-2) & $3(12.5)$ & $3(15.8)$ & \\
\hline Normal (TIMI 3) & $12(50.0)$ & $5(26.3)$ & \\
\hline Site of arterial steno-occlusion & & & $.085^{\mathrm{b}}$ \\
\hline Intracranial distal ICA & $1(4.2)$ & $5(26.3)$ & \\
\hline MCA Ml segment & $7(29.2)$ & $8(42.1)$ & \\
\hline MCA M2 segment & $4(16.7)^{\prime}$ & $1(5.3)^{\prime}$ & \\
\hline None & $12(50.0)$ & $5(26.3)$ & \\
\hline DWI lesion volume (median) (IQR) $\left(\mathrm{cm}^{3}\right)$ & $8.5(2.5-17.1)$ & $25.3(3.9-45.5)$ & .101 \\
\hline Prominent MV & & & $.003^{\mathrm{a}}$ \\
\hline MVi (No.) (\%) & $3(12.5)$ & $11(57.9)$ & $.002^{\mathrm{a}}$ \\
\hline MVc (No.). (\%) & $9(37.5)$ & $1(5.3)$ & $.026^{c}$ \\
\hline Norm (No.) (\%) & $12(50.0)$ & $7(36.8)$ & \\
\hline
\end{tabular}

Note:- IQR indicates interquartile range.

a $P<.01$.

${ }^{\mathrm{b}} \mathrm{P}<\mathrm{.1}$.

${ }^{c} P<.05$.
95\% CI, $1.04-120.03 ; P=.046)$, age (OR, 1.13; 95\% CI, $1.03-$ $1.24 ; P=.013$ ), and admission NIHSS score (OR, 1.67; $95 \%$ CI, 1.03-2.69; $P=.036$ ) were independently associated with poor clinical outcome (Table 2).

\section{Relationship of Cerebral Blood Flow to MV Prominence}

MVi were associated with a mean $64.5 \pm 18.0 \%$ (range, $33.6 \%-$ $88.3 \%$ ) decrease in $\triangle \mathrm{CBF}$; and $\mathrm{MVc}$, with a mean $52.4 \pm 22.2 \%$ (range, 30.1\%-102.4\%) increase (Fig 2). Subjective review of the $\mathrm{CBF}$ images showed that changes in $\triangle \mathrm{CBF}$ reflected decreases in $\mathrm{CBF}$ in the ipsilateral hemisphere in the presence of $\mathrm{MVi}$ and clear hyperperfusion in the presence of MVc (Fig 1). In addition to $\triangle \mathrm{CBF}(P<.001)$, other factors, including admission NIHSS score $(P=.042)$, vascular status $(P=.001)$, site of arterial steno-occlusion $(P<.001)$, and DWIlesion volume $(P<.001)$, also showed significant differences among $\mathrm{MVi}, \mathrm{MVc}$, and Norm groups (Table 3). Vascular status was highly correlated with $\triangle \mathrm{CBF}$ $(r=0.617, P<.001)$ and DWI lesion volume $(r=0.736, P<.001)$. The site of arterial steno-occlusion was highly correlated with DWI lesion volume $(r=$ $0.583, P<.001)$. Multiple logistic regression analysis showed that $\triangle \mathrm{CBF}$ was negatively related to MVi but positively associated with $\mathrm{MVc}$ (OR, 0.91; 95\% CI, $0.85-0.97 ; P=.005$; and OR, $1.22 ; 95 \%$ CI, $1.01-1.47 ; P=.037$; respectively) (Table 4).

\section{DISCUSSION}

The identification of predictive and prognostic biomarkers for patients with ischemic stroke has major potential clinical implications. In recent years, there has been increasing recognition that changes in the appearance of MV on SWI may provide novel, clinically rele-

Table 2: The factors associated with poor clinical outcome

\begin{tabular}{|c|c|c|c|c|}
\hline Variable & $\begin{array}{l}\text { Univariate Analysis } \\
\text { (OR) (95\% CI) }\end{array}$ & $P$ Value & $\begin{array}{l}\text { Multivariate Analysis } \\
\text { (OR) }(95 \% \mathrm{Cl})\end{array}$ & $P$ Value \\
\hline Age & $1.078(1.016-1.144)$ & $.013^{\mathrm{a}}$ & $1.126(1.026-1.237)$ & $.013^{\mathrm{a}}$ \\
\hline Sex & $2.167(0.617-7.603)$ & .227 & - & .768 \\
\hline Admission NIHSS score & $1.368(1.088-1.721)$ & $.007^{\mathrm{b}}$ & $1.668(1.033-2.694)$ & $.036^{\mathrm{a}}$ \\
\hline DWI lesion volume & $1.000(1.000-1.000)$ & 1.126 & - & .201 \\
\hline Prominent MV & & $.009^{b}$ & - & $.029^{\mathrm{a}}$ \\
\hline Norm & Reference & Reference & Reference & Reference \\
\hline $\mathrm{MVi}$ & $6.286(1.294-30.538)$ & $.023^{\mathrm{a}}$ & 11.188 (1.043-120.031) & $.046^{\mathrm{a}}$ \\
\hline $\mathrm{MVc}$ & $0.190(0.020-1.837)^{\prime}$ & .152 & $0.025(0.000-2.180)$ & .106 \\
\hline Site of arterial steno-occlusion & & .120 & & .637 \\
\hline None & Reference & Reference & Reference & Reference \\
\hline Intracranial distal ICA & $12.000(1.103-130.580)$ & .041 & - & .334 \\
\hline MCA M1 segment & $2.743(0.640-11.753)$ & .174 & - & .880 \\
\hline MCA M2 segment & $0.600(0.053-6.795)$ & .680 & - & .491 \\
\hline
\end{tabular}

Note:- - indicates not applicable.

a $P<.05$.

${ }^{\mathrm{b}} \mathrm{p}<.01$. 
vant biomarkers. SWI is a relatively novel technique that maximizes sensitivity to susceptibility differences, caused by the presence of paramagnetic substances, by combining a long TE, highresolution, fully flow-compensated sequence with a $3 \mathrm{D}$ gradientecho sequence. Magnitude and phase data are both used in image reconstruction, and the technique is very sensitive for the detection of microhemorrhage but also for the detection of deoxygenated venous blood. ${ }^{17-19}$ The sensitivity of SWI to high concentrations of deoxyhemoglobin produces high contrast between normal brain and venous structures, which has led to increasing interest in cerebral venous structures and venous abnormalities.

The initial observation by Morita et $\mathrm{al}^{1}$ in 2008 of prominent MV in the ipsilateral hemisphere of patients with acute stroke was rapidly confirmed and given the name of the "brush sign." Subsequent studies have shown a strong relationship between the presence of ipsilateral prominent MV and hemorrhagic transformation and outcome in patients undergoing thrombolytic therapy for hyperacute or acute stroke. ${ }^{2,3,9}$

The mechanisms producing increased prominence of MV reflect increased deoxyhemoglobin content within the imaged vox-

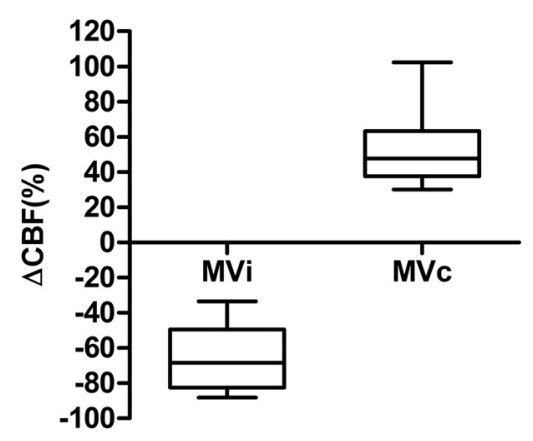

FIG 2. Changes in cerebral blood flow associated with ipsilateral and contralateral prominence of the medullary veins. els. This may, in part, reflect an increase in venous volume due to vasodilation induced by regional ischemia. ${ }^{3,7}$ However, it will also occur if the venous deoxyhemoglobin concentration is increased as a result of increases in oxygen extraction in the venous drainage territory. ${ }^{1,4-6}$ A relationship between prominent MV and continuing ischemia in the drainage territory is in keeping with the observed relationships with poor clinical outcome and hemorrhagic transformation.

In the present study, we examined the implications of prominent MV in patients with subacute ischemic stroke, diagnosed after the therapeutic window for revascularization or recanalization therapies. Our initial clinical observations demonstrated that prominent MV are seen in this scenario but also that they may be seen in the hemisphere either ipsilateral or contralateral to the stroke.

Our first hypothesis, based on the results of previous studies, was that prominent ipsilateral MV are prognostic biomarkers of poor outcome in patients with subacute ischemic stroke. This is based on an assumption that prominent MV in the ipsilateral hemisphere reflect increased oxygen extraction due to continuing ischemia in the venous drainage territory. The findings supported this hypothesis, demonstrating that MVi were an independent prognostic feature for clinical outcome with an odds ratio of $>11$ (95\% CI, 1.04-120.03; $P<.05$ ). Our second hypothesis was that prominent ipsilateral MV are associated with hypoperfusion. Once again the findings support the hypothesis, with significant decreases in $\triangle \mathrm{CBF}$ seen in association with prominent $\mathrm{MVi}$. These findings suggest that in the subacute setting, a subgroup of patients with stroke identified by the presence of MVi, have poorer clinical outcomes resulting from continued ischemia of sufficient severity to require an increase in the oxygen extraction fraction. The poor clinical outcome may result from cellular bioenergetic failure, blood-brain barrier dysfunction, and postisch-

Table 3: Clinical and imaging characteristics among MVi, MVc, and Norm groups

\begin{tabular}{|c|c|c|c|c|}
\hline Variable & MVi $(n=14)$ & $\operatorname{MVc}(n=10)$ & Norm $(n=19)$ & $P$ Value \\
\hline Age (mean) (yr) & $57.4 \pm 12.2$ & $53.5 \pm 11.2$ & $63.2 \pm 12.4$ & .113 \\
\hline Men (No.) (\%) & $10(71.4)$ & $5(50.0)$ & $10(52.6)$ & .528 \\
\hline Time to MRI examination (mean) (day) & $4.6 \pm 1.6$ & $5.5 \pm 1.4$ & $4.9 \pm 1.2$ & .312 \\
\hline Admission NIHSS score (mean) & $11.5 \pm 3.5$ & $9.9 \pm 4.3$ & $8.5 \pm 2.4$ & $.042^{\mathrm{a}}$ \\
\hline \multicolumn{5}{|l|}{ Vascular risk factors } \\
\hline Diabetes mellitus (No.) (\%) & $7(50.0)$ & $3(30.0)$ & $10(52.6)$ & .501 \\
\hline Hypertension (No.) (\%) & $6(42.9)$ & $5(50.0)$ & $7(36.8)$ & .858 \\
\hline Hyperlipidemia (No.) (\%) & $9(64.3)$ & $3(30.0)$ & $10(52.6)$ & .287 \\
\hline Smoking (No.) (\%) & $6(42.9)$ & $4(40.0)$ & $5(26.3)$ & .651 \\
\hline Drinking (No.) (\%) & $5(35.7)$ & $2(20.0)$ & $4(21.1)$ & .662 \\
\hline Lesion left location (No.) (\%) & $6(42.9)$ & $8(80.0)$ & $9(47.4)$ & .117 \\
\hline Vascular status (TIMI) & & & & $.001^{\mathrm{b}}$ \\
\hline Occlusion (TIMI 0) & $12(85.7)$ & $2(20.0)$ & $6(31.6)$ & \\
\hline Stenosis (TIMI 1-2) & $2(14.3)$ & $1(10.0)$ & $3(15.8)$ & \\
\hline Normal (TIMI 3) & $0(0.0)$ & $7(70.0)$ & $10(52.6)$ & \\
\hline Site of arterial steno-occlusion & & & & $<.001^{\mathrm{b}}$ \\
\hline Intracranial distal ICA & $4(28.6)$ & $1(10.0)$ & $1(5.3)$ & \\
\hline MCA M1 segment & $9(64.3)$ & $1(10.0)$ & $6(26.3)$ & \\
\hline MCA M2 segment & $1(7.1)$ & $1(10.0)$ & $3(15.8)$ & \\
\hline None & $0(0.0)$ & $7(70.0)$ & $10(52.6)$ & \\
\hline DWI lesion volume (median) (IQR) $\left(\mathrm{cm}^{3}\right)$ & $30.2(16.4-46.4)$ & $9.5(7.5-20.8)$ & $3.3(2.2-8.5)$ & $<.001^{\mathrm{b}}$ \\
\hline$\Delta \mathrm{CBF}$ (mean) (\%) & $-64.5 \pm 18.0$ & $52.4 \pm 22.2$ & $4.8 \pm 9.9$ & $<.001^{\mathrm{b}}$ \\
\hline
\end{tabular}

Note:- IQR indicates interquartile range.

a $P<.05$.

${ }^{\mathrm{b}} \mathrm{P}<.01$. 
Table 4: Results of multiple logistic regression analysis for the MV prominence

\begin{tabular}{|c|c|c|c|c|}
\hline \multirow[t]{2}{*}{ Variable } & \multirow[t]{2}{*}{$P$ Value } & \multirow[t]{2}{*}{ OR } & \multicolumn{2}{|c|}{$95 \% \mathrm{Cl}$} \\
\hline & & & & \\
\hline Admission NIHSS score & .987 & 1.004 & 0.604 & 1.671 \\
\hline DWI lesion volume & .217 & 1.000 & 1.000 & 1.000 \\
\hline$\Delta \mathrm{CBF}$ & $.005^{\mathrm{a}}$ & 0.910 & 0.851 & 0.972 \\
\hline$M V c$ & & & & \\
\hline Admission NIHSS score & .116 & 2.213 & 0.822 & 5.961 \\
\hline DWI lesion volume & $.023^{\mathrm{b}}$ & 1.000 & 1.000 & 1.000 \\
\hline$\Delta \mathrm{CBF}$ & $.037^{\mathrm{b}}$ & 1.217 & 1.012 & 1.464 \\
\hline
\end{tabular}

a $P<.01$.

b $p<.05$

emic inflammation, all of which are related to poor clinical outcome. $^{20}$

Our third hypothesis was that prominent contralateral MV may provide additional prognostic information. Although MVc did not provide independent significant predictive power for clinical outcome, there was a significant difference in the incidence between outcome groups with $\mathrm{MVc}$, seen in $37.5 \%$ of patients with good outcome and only $5.3 \%$ of patients with poor outcome $(P<.05)$. Prominent MVc were associated with a significant increase in $\triangle \mathrm{CBF}$, reflecting hyperperfusion in the ipsilateral hemisphere. The presence of perilesional hyperperfusion in the early postinfarct stage has been recognized for $>20$ years. $^{21,22}$ Hyperperfusion occurs in the ischemic penumbra following recanalization or reperfusion and is seen in up to $50 \%$ of patients with a mean delay of 5.8 days from ictus. ${ }^{23,24}$ There is extensive evidence that hyperperfusion causes a decreased oxygen extraction fraction and is associated with improved clinical outcome. ${ }^{22,23,25-27}$ However, there is also a link between hyperperfusion and increased risk of hemorrhagic transformation. ${ }^{28}$ The mechanism of hyperperfusion is incompletely understood, but regional increases in cerebral metabolism have been demonstrated by using MR spectroscopy, leading to the suggestion that local metabolic changes produce local vasodilation. ${ }^{25}$ Vasodilation induced by early recanalization may decrease the resistance to blood flow, allowing an increase in CBF. Other works have suggested that cerebrovascular autoregulation fails to re-establish for a time following reperfusion. ${ }^{23}$ Whatever the underlying mechanism, it is likely to represent regional decreases in cerebrovascular resistance. These unilateral changes in cerebrovascular resistance, particularly in the presence of proximal arterial occlusions, will promote collateral flow via the circle of Willis or leptomeningeal vessels. We hypothesize that prominent MVc indirectly reflect increased CBF in the ipsilateral hemisphere due to spontaneous recanalization or collateral flow, resulting in relatively decreased deoxyhemoglobin concentration in the draining veins due to excessive oxygen delivery and thus an increase in signal intensity within the medullary veins.

Our study is limited by its relatively small sample size $(n=$ 43) and cross-sectional design; therefore, our results should be interpreted cautiously. Second, both SWI and MRA data were collected at the same time point; thus, the causal relationship between change of vascular status and prominence of MV cannot be answered in the current study.

\section{CONCLUSIONS}

This study shows that prominence of MV on SWI in the hemisphere ipsilateral to stroke has significant power to predict clinical outcome, similar to that seen in patients in the acute stroke setting. We have described the relationship between the prominence of MV in the contralateral hemisphere and good clinical outcome which, we hypothesize, reflects the development of penumbral hypoperfusion in combination with spontaneous recanalization or active collateral flow via the circle of Willis or leptomeningeal vessels.

Disclosures: Peiyu Huang_UNRELATED: Grants/Grants Pending: National Natural Science Foundation of China.* Quan Jiang_UNRELATED: National Institutes of Health (R01 NS64134). Minming Zhang—RELATED: National Natural Science Foundation of China (No. 81271530) and the Zhejiang Provincial Natural Science Foundation of China (No. LZ14H180001); UNRELATED: Grants/Grants Pending: National Natural Science Foundation of China. ${ }^{*}$ Money paid to the institution.

\section{REFERENCES}

1. Morita N, Harada M, Uno $M$, et al. Ischemic findings of $T 2{ }^{*}$ weighted 3-Tesla MRI in acute stroke patients. Cerebrovasc Dis 2008 ; 26:367-75 CrossRef Medline

2. Terasawa Y, Yamamoto N, Morigaki R, et al. Brush sign on 3-T T2* weighted MRI as a potential predictor of hemorrhagic transformation after tissue plasminogen activator therapy. Stroke 2014;45: 274-76 CrossRef Medline

3. Rosso C, Belleville M, Pires C, et al. Clinical usefulness of the visibility of the transcerebral veins at $3 \mathrm{~T}$ on $\mathrm{T} 2^{\star}$-weighted sequence in acute stroke patients. Eur J Radiol 2012;81:1282-87 CrossRef Medline

4. Tamura H, Hatazawa J, Toyoshima H, et al. Detection of deoxygenation-related signal change in acute ischemic stroke patients by T2*-weighted magnetic resonance imaging. Stroke 2002;33:967-71 CrossRef Medline

5. Kesavadas C, Santhosh K, Thomas B. Susceptibility weighted imaging in cerebral hypoperfusion: can we predict increased oxygen extraction fraction? Neuroradiology 2010;52:1047-54 CrossRef Medline

6. Haacke EM, Xu Y, Cheng YC, et al. Susceptibility weighted imaging (SWI). Magn Reson Med 2004;52:612-18 CrossRef Medline

7. Hermier M, Nighoghossian N, Derex L, et al. Hypointense transcerebral veins at $\mathrm{T} 2{ }^{*}$-weighted MRI: a marker of hemorrhagic transformation risk in patients treated with intravenous tissue plasminogen activator. J Cereb Blood Flow Metab 2003;23:1362-70 Medline

8. Hermier M, Nighoghossian N, Derex L, et al. Hypointense leptomeningeal vessels at $\mathrm{T} 2{ }^{*}$-weighted MRI in acute ischemic stroke. Neurology 2005;65:652-53 CrossRef Medline

9. Lou M, Chen Z, Wan J, et al. Susceptibility-diffusion mismatch predicts thrombolytic outcomes: a retrospective cohort study. AJNR Am J Neuroradiol 2014;35:2061-67 CrossRef Medline

10. Reinhard M, Roth M, Guschlbauer B, et al. Dynamic cerebral autoregulation in acute ischemic stroke assessed from spontaneous blood pressure fluctuations. Stroke 2005;36:1684-89 CrossRef Medline

11. Kasner SE. Clinical interpretation and use of stroke scales. Lancet Neurol 2006;5:603-12 CrossRef Medline

12. Denk C, Rauscher A. Susceptibility weighted imaging with multiple echoes. J Magn Reson Imaging 2010;31:185-91 CrossRef Medline

13. Horie N, Morikawa M, Nozaki A, et al. "Brush sign" on susceptibility-weighted MR imaging indicates the severity of Moyamoya disease. AJNR Am J Neuroradiol 2011;32:1697-702 CrossRef Medline

14. Jørgensen HS, Sperling B, Nakayama H, et al. Spontaneous reperfusion of cerebral infarcts in patients with acute stroke: incidence, 
time course, and clinical outcome in the Copenhagen Stroke Study. Arch Neurol 1994;51:865-73 CrossRef Medline

15. Neumann-Haefelin T, Wittsack HJ, Fink GR, et al. Diffusion- and perfusion-weighted MRI: influence of severe carotid artery stenosis on the DWI/PWI mismatch in acute stroke. Stroke 2000;31:1311-17 CrossRef Medline

16. Fiebach JB, Al-Rawi Y, Wintermark M, et al. Vascular occlusion enables selecting acute ischemic stroke patients for treatment with desmoteplase. Stroke 2012;43:1561-66 CrossRef Medline

17. Haddar D, Haacke E, Sehgal V, et al. Susceptibility weighted imaging: theory and applications [in French]. J Radiol 2004;85: 1901-08 CrossRef Medline

18. Mittal S, Wu Z, Neelavalli J, et al. Susceptibility-weighted imaging: technical aspects and clinical applications, part 2. AJNR Am J Neuroradiol 2009;30:232-52 Medline

19. Haacke EM, Mittal S, Wu Z, et al. Susceptibility-weighted imaging: technical aspects and clinical applications, part 1. AJNR Am J Neuroradiol 2009;30:19-30 Medline

20. Brouns R, De Deyn P. The complexity of neurobiological processes in acute ischemic stroke. Clin Neurol Neurosurg 2009;111:483-95 CrossRef Medline

21. Marchal G, Serrati C, Rioux P, et al. PET imaging of cerebral perfusion and oxygen consumption in acute ischaemic stroke: relation to outcome. Lancet 1993;341:925-27 CrossRef Medline

22. Marchal G, Furlan M, Beaudouin V, et al. Early spontaneous hyper- perfusion after stroke: a marker of favourable tissue outcome? Brain 1996;119:409-19 CrossRef Medline

23. Bivard A, Stanwell P, Levi C, et al. Arterial spin labeling identifies tissue salvage and good clinical recovery after acute ischemic stroke. J Neuroimaging 2013;23:391-96 CrossRef Medline

24. Bowler JV, Wade JP, Jones BE, et al. Natural history of the spontaneous reperfusion of human cerebral infarcts as assessed by $99 \mathrm{mTc}$ HMPAO SPECT. J Neurol Neurosurg Psychiatry 1998;64:90-97 CrossRef Medline

25. Bivard A, Krishnamurthy V, Stanwell P, et al. Spectroscopy of reperfused tissue after stroke reveals heightened metabolism in patients with good clinical outcomes. J Cereb Blood Flow Metab 2014;34: 1944-50 CrossRef Medline

26. Takamatsu H, Tsukada H, Kakiuchi T, et al. Detection of reperfusion injury using PET in a monkey model of cerebral ischemia. $\mathrm{J} \mathrm{Nucl}$ Med 2000;41:1409-16 Medline

27. Kaku Y, Iihara K, Nakajima N, et al. Cerebral blood flow and metabolism of hyperperfusion after cerebral revascularization in patients with moyamoya disease. J Cereb Blood Flow Metab 2012;32:2066-75 CrossRef Medline

28. Yu S, Liebeskind DS, Dua S, et al; UCLA Stroke Investigators. Postischemic hyperperfusion on arterial spin labeled perfusion MRI is linked to hemorrhagic transformation in stroke. J Cereb Blood Flow Metab 2015;35:630-37 CrossRef Medline 